\title{
Optimum Timing and Complication of Completion Thyroidectomy for Differentiated Thyroid Cancer
}

\author{
Mohamed Abouelmagd Salem, Badawy M. Ahmed, Mahmoud H. Elshoieby \\ Surgical Oncology Department, SECI, Assiut University, Assiut, Egypt \\ Email: badawy_znatyy@yahoo.co.uk
}

How to cite this paper: Salem, M.A., Ahmed, B.M. and Elshoieby, M.H. (2017) Optimum Timing and Complication of Completion Thyroidectomy for Differentiated Thyroid Cancer. Journal of Cancer Therapy, 8, 518-526.

https://doi.org/10.4236/jct.2017.85044

Received: April 17, 2017

Accepted: May 28, 2017

Published: May 31, 2017

Copyright $\odot 2017$ by authors and Scientific Research Publishing Inc. This work is licensed under the Creative Commons Attribution International License (CC BY 4.0).

http://creativecommons.org/licenses/by/4.0/

\begin{abstract}
Background: Despite improved preoperative diagnostics, incidental postoperative detection of differentiated thyroid cancer in the final histology is still common. In most of these cases, completion thyroidectomy is recommended by national and international guidelines, although secondary surgery is associated with an increased operative risk. The optimal timing of completion thyroidectomy is still controversial. Patients and Methods: The patients admitted to surgical oncology department, SECI, with diagnosis of differentiated thyroid cancer; during the period from January 2008 to December 2015; were rewired for age, sex, type of $1^{\text {st }}$ operation, histopathological result, type of $2^{\text {nd }}$ operation and time interval between the 2 operation, complication of $2^{\text {nd }}$ operation and morbidity. 118 patients underwent completion thyroidectomy; those patients were divided according to timing of completion operation into 3 groups: Group A is from one week to 3 months and include 64 patients; Group B is from 3 - 6 months and include 30 patients; Group C is more than 6 months and include 24 patients. Clinical complications and oncologic outcomes were analyzed. The mean follow-up was $80 \pm 10$ months. Result: we record 118 patients under completion thyroidectomy. Ages range from 79 to 13 years. Papillary thyroid cancer were 96 and follicular thyroid cancer were 22. The overall rates of transient and persistent postoperative hypocalcemia were $19.5 \%$ and $4.2 \%$, respectively. The rates of persistent hypocalcemia were found in group A and B but not in group C. Transient or persistent vocal cord paresis was observed in $9(7.6 \%)$ and 3 patients $(2.5 \%)$. The incidence of persistent vocal cord paresis ( $\mathrm{VCP}$ ) was significantly higher in groups A and $\mathrm{B}$ than in group $C$. There was no significant difference regarding survival among the 3 groups; however recurrence is higher in group A. Conclusion: Considering perioperative morbidity and oncologic outcomes, completion thyroidectomy should be performed at least 3 to 6 months after primary surgery.
\end{abstract}




\section{Keywords}

Optimum Timing, Completion Thyroidectomy

\section{Background}

Thyroid cancer is the most common endocrine malignancy, with 62980 estimated new cases in the United States in 2014 [1].

Papillary thyroid carcinoma (PTC) accounts for about $80 \%$ to $90 \%$ of all thyroid cancers [1] [2]. The long-term prognosis is usually excellent with a 10-year survival rate of up to $98 \%$ [1] [3] [4].

Differentiated thyroid cancer is a usual disease of the thyroid gland and, if totally excised, is associated with excellent prognosis. They can be diagnosed by sonography, scintigraphy, tumor markers CT, and in exact cases fine-needle biopsy are useful in detecting or at least questioning thyroid malignancies, particularly in patients with multinodular goiter. Additionally, intraoperative frozen section may be useful to avoid an incomplete resection in patients with thyroid malignancies. On the other hand, in up to $10 \%$ of patients histological surprise of cancer thyroid were detected postoperatively in patients whose operated on for benign thyroid disease [1] [5] [6] [7] [8] [9].

In most of these cases completion thyroidectomy is recommended by national and international guidelines [5]. Clinical diagnostics (e.g., cervical ultrasonography, thoracic radiography, tumor markers) should be undertaken before completion thyroidectomy when it is necessary.

While the indications for completion thyroidectomy for thyroid cancer diagnosed postoperatively are without excessive debate, the timing of such operation is still a matter of controversy [6]. Thus, in the current study we retrospectively evaluated 118 patients who underwent completion thyroidectomy at different time intervals after primary operation in regard to perioperative complications and long-term oncologic outcome.

\section{Patient and Methods}

During the period from January 2008 to December 2015; we record 232 patients with malignant thyroid out of total number of 683 patients with diagnosis of thyroid pathology during the previous period. Only 157 patients had complete data in patient's sheet. 118 patients under completion thyroidectomy for differentiated thyroid cancer. The other 39 patients underwent total thyroidectomy in $1^{\text {st }}$ operation. 125 with papillary thyroid cancer (PTC) 18 with follicular thyroid cancer (FTC) 7 medullary thyroid cancer and 9 with other pathology at surgical oncology department, South Egypt Cancer Institute (SECI), Assiut University.

Completion thyroidectomy were indicated for tumor diameter more than 1 $\mathrm{cm}(\mathrm{n}=35)$, infiltration of the thyroid capsule $(\mathrm{n}=27)$, large thyroid mass left behind after primary surgery $(\mathrm{n}=30), \mathrm{R} 1$ resection of thyroid carcinoma $(\mathrm{n}=$ 
15), and radioactive residual at thyroid bed $(\mathrm{n}=60)$.

In all, 90 patients (76.3\%) underwent the initial thyroid resection in hospitals without preoperative histological diagnosis were referred to our institution for their secondary surgery after the diagnosis of thyroid malignancy.

Five patients showed tumors larger than $1 \mathrm{~cm}$ and capsular infiltration. Sven of fifteen patients with a large thyroid mass left behind after primary surgery additionally had tumor infiltration of the thyroid capsule.

In all patients (118), secondary surgery included operative procedures on the previously operated side, such as resection of residual thyroid tissue, removal whole thyroid tissue in other side and at least central lymph node dissection. In patients with PTC more than $1 \mathrm{~cm}$, prophylactic central and lateral lymph node dissection on both sides was performed routinely following our standard operating procedures.

The patients were divided according to timing of completion operation into 3 groups regarding the time of secondary operation. Group A from one week to 3 months and include 64 patients, Group B from 3 - 6 months and include 30 patients, Group C more than 6 months and include 24 patients.

All patients underwent preoperative evaluation including thyroid sonar, laboratory testing, and thyroid scan before the thyroid surgery. Vocal cord examination and serum calcium levels were routinely examined before and after secondary surgery in all patients.

At SECI, the normal range for serum calcium is $2.0-2.6 \mathrm{mmol} / \mathrm{L}$. Postoperative supplementation was started at serum calcium levels $/ 2.0 \mathrm{mmol} / \mathrm{L}$ and/or in case of clinical symptoms.

Scheduled follow-up examinations were performed in all patients, including sonography and determination of tumor markers. An iodine-131 whole-body scan was performed at $3-4$ months, 1 and 5 years after the completion thyroidectomy. In case of increased tumor markers or other signs of disease recurrence, additional diagnostics-e.g., computed tomography (CT), magnetic resonance imaging, were performed where applicable.

Patient data were statistically analyzed using SPSS for Windows version 15.0 (SPSS GmbH, Mu nchen, Germany). The p values were calculated using crosstabulation and the v2 test; $\backslash 0.05$ was defined as statistically significant.

Clinical complications and oncologic outcomes were analyzed. The mean follow-up was $80 \pm 10$ months.

\section{Results}

\subsection{Patient Characteristics}

A total of 96 patients underwent completion thyroidectomy for PTC and 22 patients for FTC. The mean age at the time of surgery was 41.7 years (Age range from 79 to 13 years,). There were 90 (76\%) women and 28 (24\%) men.

\subsection{Operative Data}

Right completion thyroidectomy was essential in 23 patients (19\%) and left 
completion thyroidectomy in 27 patients (23\%), respectively. In all, 68 patients underwent completion thyroidectomy on both sides (58\%).

Lymph node dissection was done in 99 patients (84\%) (Table 1): 68 patients (58\%) underwent central lymph node dissection on both sides and 31 patients (26\%) underwent lateral lymphadenectomy (ipsilateral, $\mathrm{n}=21$; contralateral, $\mathrm{n}=$ 10). All patients had to be reoperated on the side of the primary operation for resection of remaining thyroid tissue and/or lymph node dissection. The mean number of dissected lymph nodes was 13 (range 5 - 33).

Adhesions were documented in 71 patients (60\%). In 53 cases these adhesions were described as severe (45\%). There was significant difference between the three groups (groups A-C) where sever adhesion more in group A. Auto transplantation of parathyroid glands had to be performed in 7 patients due to accidental removal or intraoperative affection of the blood supply.

\subsection{Histology}

In the final histology, 30 patients exhibited multicenteric thyroid carcinoma

Table 1. Patient groups, characteristics and complication.

\begin{tabular}{|c|c|c|c|c|}
\hline $\begin{array}{c}\text { Timing of CT } \\
\text { (after primary surgery) }\end{array}$ & $\begin{array}{l}\text { Group A } \\
1 \text { week to } \\
3 \text { months }\end{array}$ & $\begin{array}{l}\text { Group B } \\
3 \text { month to } \\
6 \text { month }\end{array}$ & $\begin{array}{l}\text { Group C } \\
\text { More than } \\
6 \text { month }\end{array}$ & Total \\
\hline No. of patients & $64(54 \%)$ & $30(26 \%)$ & $24(20 \%)$ & 118 \\
\hline $\begin{array}{l}\text { Primary Surgery } \\
\text { - } \quad \text { Hemi-thyroidectomy } \\
\text { - } \quad \text { Subtotal } \\
\text { - } \quad \text { Near total } \\
\text { - } \quad \text { Total }\end{array}$ & $\begin{array}{c}31 \\
13 \\
9 \\
9\end{array}$ & $\begin{array}{c}12 \\
3 \\
3 \\
12\end{array}$ & $\begin{array}{c}6 \\
2 \\
3 \\
13\end{array}$ & $\begin{array}{l}49 \\
18 \\
17 \\
34\end{array}$ \\
\hline $\begin{array}{l}\text { Completion thyroidectomy } \\
\text { - } \quad \text { Right CT } \\
\text { - } \quad \text { Left CT } \\
\text { - } \quad \text { Bilateral CT }\end{array}$ & $\begin{array}{c}12 \\
14 \\
37(58 \%)\end{array}$ & $\begin{array}{c}6 \\
7 \\
37(58 \%)\end{array}$ & $\begin{array}{c}5 \\
5 \\
15(63 \%)\end{array}$ & $\begin{array}{l}23 \\
27 \\
68\end{array}$ \\
\hline $\begin{array}{l}\text { No. with pLND } \\
\text { No. with tLND }\end{array}$ & $\begin{array}{l}35(55 \%) \\
15(23 \%)\end{array}$ & $\begin{array}{l}17(57 \%) \\
10(33 \%)\end{array}$ & $\begin{array}{c}16(67 \%) \\
6(25 \%)\end{array}$ & $\begin{array}{l}68 \\
31\end{array}$ \\
\hline $\begin{array}{r}\text { Pathology } \\
\text { - } \quad \text { Papillary } 96(81 \%) \\
\text { - Follicular 22 (19\%) }\end{array}$ & $\begin{array}{l}53 \\
11\end{array}$ & $\begin{array}{c}22 \\
8\end{array}$ & $\begin{array}{c}21 \\
3\end{array}$ & $\begin{array}{l}96 \\
22\end{array}$ \\
\hline \begin{tabular}{ll} 
& \multicolumn{1}{c}{ Sex } \\
- & Female $90(76 \%)$ \\
- & Male 28 $(24 \%)$
\end{tabular} & $\begin{array}{l}52 \\
12\end{array}$ & $\begin{array}{c}21 \\
9\end{array}$ & $\begin{array}{c}17 \\
7\end{array}$ & $\begin{array}{l}90 \\
28\end{array}$ \\
\hline & Morbidity & & & 28 \\
\hline $\begin{array}{l}\text { - Hypocalcemia } \\
\text { Transient } \\
\text { Persistent }\end{array}$ & $\begin{array}{c}15(23.4 \%) \\
12(18.75 \%) \\
3(4.7 \%)\end{array}$ & $\begin{array}{c}6(20 \%) \\
4(13.3 \%) \\
2(6.6 \%)\end{array}$ & $\begin{array}{c}4(16.6 \%) \\
4(16.6 \%) \\
0^{\star *}\end{array}$ & $\begin{array}{c}25 \\
23(19.5 \%) \\
2(4.2 \%)\end{array}$ \\
\hline $\begin{array}{l}\text { - Vocal cord paresis } \\
\text { Transient } \\
\text { Persistent }\end{array}$ & $\begin{array}{l}8(12.5 \%) \\
6(9.3 \%) \\
2(3.1 \%)\end{array}$ & $\begin{array}{l}3(10 \%) \\
2(6.7 \%) \\
1(3.3 \%)\end{array}$ & $\begin{array}{c}1(4 \%) \\
1(4 \%) \\
0^{* *}\end{array}$ & $12(10 \%)$ \\
\hline Residual tumor & 33 & 18 & 11 & 62 \\
\hline Positive LN & 27 & 16 & 13 & 56 \\
\hline
\end{tabular}

CT: completion thyroidectomy, bCT: bilateral completion thyroidectomy, pLND: prophylactic lymph node (ln) dissection (ln-), tLND: therapeutic lymph node dissection ( $\ln$ ?), ${ }^{* *}$ p value $<0.005$. 
(25.5\%). PTC (27/96) was diagnosed in 23 of these patients and four patients had PTC with an FTC variant, and three patients had invasive FTC. In 62 cases the completion thyroidectomy specimen comprised residual tumor (52.5\%). Twenty eight patients showed contralateral secondary cancer (24\%). No additional tumor cells were detected histologically after completion thyroidectomy in 56 patients $(47.5 \%)$. Lymph node positive in 56 patients (47.5\%). PTC was diagnosed in 53 of these patients.

\subsection{Perioperative Morbidity}

Particular postoperative complications after completion thyroidectomy were hypocalcemia and vocal cord paresis (VCP). Twenty five patients developed transient postoperative hypocalcemia (21\%). five patients required long-term IV and oral calcium substitution for persistent hypoparathyroidism (4.2\%). The rates of persistent hypocalcemia were significantly higher in groups A, and B as compared to those of groups C ( $\mathrm{p}<0.005)$ (Table 1$)$. Transient VCP was detected in twelve patients $(10 \%)$ and persistent VCP in three patients $(2.5 \%)$. Recurrent laryngeal nerve (RLN) palsy happened more frequently in groups A and $B(p<0.005)$ (Table 1$)$. There was persistant bilateral VCP in one patient, in whom transient tracheotomy had to be performed. Other morbidity include pleural injury in one patient in group A, Horner's syndromes in 2 patients one in group $\mathrm{A}$ and the other in group $\mathrm{C}$.

Multiple surgeries were performed in 9 patients where 2 patients develop transient hypocalcemia.

\subsection{Follow-Up Data}

Postoperative radioactive iodine treatment was achieved in 112 patients (95\%). The mean number of therapy courses was two (range $1-7$ ). At the time of follow-up 107 patients were thriving and disease-free (90.5\%). Twelve patients $(10.3 \%)$ were treated for local recurrence $(n=9)$ or distant metastasis $(n=3)$. Two patients developed bone metastasis from FTC and one patient developed lung metastasis from PTC with follicular element. The PTC patient additionally showed loco-regional metastases.

Nine patients died during the follow-up. Two of these seven patients died disease progression and seven patients for other causes. Because of the low number of events (two), the cancer related overall survival could not be considered. Nevertheless, there was no important difference among the three groups regarding disease-free survival during the follow-up.

\section{Discussion}

\subsection{Indication for Completion Thyroidectomy}

The indication for completion thyroidectomy in patients with incidentally established differentiated thyroid tumor after primary thyroid operation should consider patient-related, tumor-related, and treatment-related criteria [6]. 
In the current study 96 of 118 patients had PTC. This object is frequently concomitant with local lymph node metastasis. Furthermore, multicenter tumor localization is common [10] [11] [12].

Auguste and Attie [13] reported multifocal PTC in 33 of 80 patients (41.2\%) and contralateral PTC in 30 of 80 patients (37.5\%) after completion thyroidectomy. In current series, the general rate of multifocal PTC was $28 \%$ (27/96). Multicenteric tumor localization has been presented to be accompanying with a higher risk of lymph node metastasis and local lymph node recurrence [10]. Thus, secondary total thyroidectomy and local lymph node dissection should be completed in all cases except patients with unifocal papillary microcarcinoma (> $1 \mathrm{~cm}$ ) without metastasis and/or infiltration of the thyroid capsule [14] [15].

In the current study, 22 patients (19\%) were operated on for FTC. three of these patients had multifocal FTC (13.5\%). It is well reported that hematogenous distant metastases can be found in $10 \%$ of patients with minimally invasive FTC and $50 \%$ of patients with widely invasive FTC. Thus, complete thyroidectomy is advised in all patients with FTC. The need of completion thyroidectomy after R0 resection during primary subtotal thyroidectomy in minimally invasive FTC without vessel infiltration or metastasis remains controversial [5] [14].

Still, suspicious nodules could be frequently detected after incomplete thyroidectomy by high-resolution ultrasonography [16].

Lymph node dissection should be performed in all patients with node-positive FTC [14] [15].

In 62 patients remaining tumor was detected histologically in the secondary resected sampling in our series (52.5\%), supporting the indication for completion thyroidectomy in most patients with differentiated thyroid carcinomas.

\subsection{Timing of Completion Thyroidectomy}

It is away from question that secondary cervical operation, if made on the ipsilateral side, increases the operational hazard after subtotal thyroidectomy. In the current study, the rate of persistent VCP and persistent hypocalcemia was $0 \%$ in groups $\mathrm{C}$ ( $<6$ months after primary surgery) (Table 1$)$. There was a major increase in transient and persistent postoperative $\mathrm{VCP}$ groups $\mathrm{A}$ and $\mathrm{B}$ ranging from $3.1 \%$ to $9.3 \%$ and $3.3 \%$ to $6.7 \%$ respectively $(\mathrm{p}<0.005)$. In the literature, the rate of transient VCP is about $20 \%$ and the rate of permanent VCP ranges between $1.5 \%$ and 5.3\% [16] [17] [18]. Reports of persistent hypocalcemia rates range between $1 \%$ and $4 \%$ in our study rate of persistent hypocalcemia range from $4.7 \%$ to $6.6 \%$ for group A and B respectively [13] [16] [19].

The impact of the timing of secondary operation on postoperative morbidity is still debatable. In some reported studies, the frequency of postoperative complications was independent of the period between the primary and completion operations [17] [20] [21] [22].

In two of these studies the rates of persistent VCP were $1.6 \%$ and $2.7 \%$, respectively. Persistent hypocalcemia occurred in $4.8 \%$ and $0.9 \%$ of patients after 
completion thyroidectomy [17] [21].

In contrast, Walgenbach and Junginger [16] described decreased postoperative morbidity in patients operated on within the first week or 3 months after primary operation. The rates of transient VCP were 5.2\% in patients with completion thyroidectomy within 1 week or after 3 months and $20.5 \%$ with the operation between 8 days and 3 months. The rate of persistent VCP was also expressively higher in patients operated on between 8 days and 3 months after primary surgery. Tan et al. [23] reported rates of transient hypocalcemia in 3.1\% for $<10$ days or $>3$ months and $10.8 \%$ for between 10 and 90 days after primary operation, respectively. There was no persistent hypocalcemia in this series. The rise in morbidity between 1, 3, and 6 months after incomplete thyroidectomy described in our study may be due to strong postoperative fibrosis and adhesions, which often decrease or entirely disappear after that period. Interestingly, there was no significant difference regarding the overall rate of patients with adhesions among the 3 groups. However, due to retrospective data analysis from surgical reports without using defined adhesion scores, the informative value regarding intraoperative adhesions is strongly predisposed by the surgeon's subjective estimation and is therefore imperfect.

The early histopathologic diagnosis of thyroid tumor is essential to permit early completion surgery. Thus, intraoperative frozen section assessment is recommended, particularly in patients with signs of malignancy. If frozen section is not accessible, a proper histopathologic diagnosis should be offered within 48 - $72 \mathrm{~h}$, following the German Association of Endocrine Surgeons practice guidelines [24]. In patients with follicular neoplasm, an intraoperative diagnosis of malignancy may be challenging because follicular lesion often necessitate detailed analysis to detect capsule infiltration or vascular invasion [25]. Also in these cases, conclusive histopathologic diagnosis should be available within $72 \mathrm{~h}$.

For this reason our study did not include patients where secondary operation done during $1^{\text {st }}$ week of primary surgery as final diagnosis usually established after one week.

\subsection{Oncologic Outcome}

In addition to perioperative morbidity, the oncologic outcome of patients with differentiated thyroid tumor after incomplete thyroidectomy must be taken into account regarding the indications and timing of completion surgery. Considering the small number of patients and the limited follow-up time, there was no important difference between the 3 groups regarding tumor recurrence or disease progression in our series.

In agreement with this trend, Walgenbach and Junginger [16], in a larger study, reported no effect of the timing of the completion thyroidectomy on survival or recurrence. Scheumann et al. [26] showed that completion thyroidectomy within 6 months of the primary surgery significantly reduced the risk of recurrence and lymph node and hematogenous spread. It also improves survival in contrast to patients in whom the second operation was delayed for longer than 6 
months. Furthermore, there is no evidence of metastasis arising from existing metastases of differentiated thyroid tumor. Nevertheless, an increased risk of disease progression after R1 or R2 resection has to be assumed. In our belief, at least 3 to 6 month interval between primary and secondary surgery can be justified.

\section{Conclusion}

Considering perioperative morbidity and oncologic outcomes, completion thyroidectomy should be performed at least 3 to 6 months after primary surgery.

\section{Conflict of Interest}

None of the authors has conflict of interest to declare.

\section{References}

[1] Donatini, G., et al. (2015) Partial Thyroidectomy for Papillary Thyroid Microcarcinoma: Is Completion Total Thyroidectomy Indicated? World Journal of Surgery.

[2] Davies, L. and Welch, H.G. (2006) Increasing Incidence of Thyroid Cancer in the United States, 1973-2002. The Journal of the American Medical Association, 295, 2164-2147. https://doi.org/10.1001/jama.295.18.2164

[3] Matsuzu, K., et al. (2014) Thyroid Lobectomy for Papillary Thyroid Cancer: Long-Term Follow-Up Study of 1,088 Cases. World Journal of Surgery, 38, 68-79. https://doi.org/10.1007/s00268-013-2224-1

[4] Bilimoria, K.Y., et al. (2007) Extent of Surgery Affects Survival for Papillary Thyroid Cancer. Annals of Surgery, 246, 375-384. https://doi.org/10.1097/SLA.0b013e31814697d9

[5] Retraction. Antiemetic Efficacy of Low-Dose Midazolam in Patients Undergoing Thyroidectomy. Otolaryngology—Head and Neck Surgery, 146, 686.

[6] Glockzin, G., et al. (2012) Completion Thyroidectomy: Effect of Timing on Clinical Complications and Oncologic Outcome in Patients with Differentiated Thyroid Cancer. World Journal of Surgery, 36, 1168-1173. https://doi.org/10.1007/s00268-012-1484-5

[7] Agarwal, G. and Aggarwal, V. (2008) Is Total Thyroidectomy the Surgical Procedure of Choice for Benign Multinodular Goiter? An Evidence-Based Review. World Journal of Surgery, 32, 1313-1324. https://doi.org/10.1007/s00268-008-9579-8

[8] Reeve, T.S., Delbridge, L. and Crummer, P. (1986) Total Thyroidectomy in the Management of Differentiated Thyroid Cancer: A Review of 258 Cases. Australian and New Zealand Journal of Surgery, 56, 829-833. https://doi.org/10.1111/j.1445-2197.1986.tb01834.x

[9] Schmid, K.W., et al. (1987) Papillary Carcinoma of the Thyroid Gland. Analysis of 94 Cases with Preoperative Fine Needle Aspiration Cytologic Examination. Acta Cytologica, 31, 591-594.

[10] Chow, S.M., et al. (2003) Papillary Microcarcinoma of the Thyroid-Prognostic Significance of Lymph Node Metastasis and Multifocality. Cancer, 98, 31-40. https://doi.org/10.1002/cncr.11442

[11] Grigsby, P.W., et al. (2006) Contralateral Papillary Thyroid Cancer at Completion Thyroidectomy Has No Impact on Recurrence or Survival after Radioiodine Treatment. Surgery, 140, 1043-1049. https://doi.org/10.1016/j.surg.2006.08.007 
[12] Dietlein, M., et al. (2005) Incidental Multifocal Papillary Microcarcinomas of the Thyroid: Is Subtotal Thyroidectomy Combined with Radioiodine Ablation Enough? Nuclear Medicine Communications, 26, 3-8. https://doi.org/10.1097/00006231-200501000-00002

[13] Auguste, L.J. and Attie, J.N. (1990) Completion Thyroidectomy for Initially Misdiagnosed Thyroid Cancer. Otolaryngologic Clinics of North America, 23, 429-439.

[14] Pacini, F., et al. (2006) European Consensus for the Management of Patients with Differentiated Thyroid Carcinoma of the Follicular Epithelium. European Journal of Endocrinology, 154, 787-803. https://doi.org/10.1530/eje.1.02158

[15] Cooper, D.S., et al. (2009) Revised American Thyroid Association Management Guidelines for Patients with Thyroid Nodules and Differentiated Thyroid Cancer. Thyroid, 19, 1167-1214. https://doi.org/10.1089/thy.2009.0110

[16] Walgenbach, S. and Junginger, T. (2002) Is the Timing of Completion Thyroidectomy for Differentiated Thyroid Carcinoma Prognostic Significant? Zentralblatt Fur Chirurgie, 127, 435-438. https://doi.org/10.1055/s-2002-31973

[17] Lefevre, J.H., et al. (2007) Reoperative Surgery for Thyroid Disease. Langenbeck's Archives of Surgery, 392, 685-691. https://doi.org/10.1007/s00423-007-0201-6

[18] Roeher, H.D., et al. (1993) Principals of Limited or Radical Surgery for Differentiated Thyroid Cancer. Thyroidology, 5, 93-96.

[19] Orsenigo, E., et al. (1997) Modified Neck Dissection in the Treatment of Differentiated Thyroid Carcinoma. European Journal of Surgical Oncology, 23, 286-288. https://doi.org/10.1016/S0748-7983(97)90561-8

[20] Dewil, B., et al. (2005) Completion Thyroidectomy after the Unexpected Diagnosis of Thyroid Cancer. B-ENT, 1, 67-72.

[21] Makay, O., et al. (2006) Completion Thyroidectomy for Thyroid Cancer. Acta Chirurgica Belgica, 106, 528-531. https://doi.org/10.1080/00015458.2006.11679945

[22] Kim, E.S., et al. (2004) Completion Thyroidectomy in Patients with Thyroid Cancer Who Initially Underwent Unilateral Operation. Clinical Endocrinology, 61, 145 148. https://doi.org/10.1111/j.1365-2265.2004.02065.x

[23] Tan, M.P., et al. (2002) Impact of Timing on Completion Thyroidectomy for Thyroid Cancer. British Journal of Surgery, 89, 802-804. https://doi.org/10.1046/j.1365-2168.2002.02068.x

[24] Musholt, T.J., et al. (2011) German Association of Endocrine Surgeons Practice Guidelines for the Surgical Treatment of Benign Thyroid Disease. Langenbeck's Archives of Surgery, 396, 639-649. https://doi.org/10.1007/s00423-011-0774-y

[25] LiVolsi, V.A. and Baloch, Z.W. (2005) Use and Abuse of Frozen Section in the Diagnosis of Follicular Thyroid Lesions. Endocrine Pathology, 16, 285-293. https://doi.org/10.1385/EP:16:4:285

[26] Scheumann, G.F., et al. (1996) Completion Thyroidectomy in 131 Patients with Differentiated Thyroid Carcinoma. European Journal of Surgery, 162, 677-684. 